\title{
Correction to: Learning process of laparoscopic liver resection and postoperative outcomes: chronological analysis of single-center 15-years' experience
}

Tomoaki Yoh $^{1}$ (1) - Satoru Seo ${ }^{1} \cdot$ Satoshi Ogiso ${ }^{1} \cdot$ Koshiro Morino $^{1} \cdot$ Takahiro Nishio $^{1} \cdot$ Yukinori Koyama ${ }^{1}$. Ken Fukumitsu ${ }^{1} \cdot$ Takamichi Ishii $^{1} \cdot$ Kojiro Taura $^{1} \cdot$ Etsuro Hatano $^{1}$

Published online: 26 October 2021

(c) The Author(s), under exclusive licence to Springer Science+Business Media, LLC, part of Springer Nature 2021

Correction to: Surgical Endoscopy

https://doi.org/10.1007/s00464-021-08660-2

This article was updated to correct Etsuro Hatano's name in the author listing.

Publisher's Note Springer Nature remains neutral with regard to jurisdictional claims in published maps and institutional affiliations.

The original article can be found online at https://doi.org/10.1007/ s00464-021-08660-2.

Satoru Seo

rutosa@kuhp.kyoto-u.ac.jp

1 Division of Hepato-Biliary-Pancreatic Surgery

and Transplantation, Department of Surgery, Graduate

School of Medicine, Kyoto University, 54 Kawahara-cho,

Shogoin, Sakyo-ku, Kyoto 606-8507, Japan 